\title{
Earth Observation in Support of Urban Resilience and Climate Adaptabil- ity Plans
}

\author{
C. Cartalis ${ }^{*}$, A. Polydoros, Th. Mavrakou and D.N. Asimakopoulos \\ Department of Environmental Physics, Panepistimiopolis, Build PHYS-V, Athens 157 84, Greece
}

\begin{abstract}
Resilience and climate adaptability plans for the thermal environment at the urban scale describe the measures to control anthropogenic heat sources in view of reducing skin and air temperatures. Such plans are based either on field measurements and/or simulations to define the energy budget at the urban scale as well as of the energy exchange between urban elements of various types. In terms of the simulations, thorough knowledge of a number of urban parameters such as land surface albedo, land surface emissivity, land surface temperature and land use/land cover is required. In this paper, the potential of Earth Observation to support the extraction and spatial/temporal representation of the above parameters is presented, especially with respect to the development of resilience and climate adaptability plans for the thermal environment at the urban scale. The potential of Earth Observation is assessed, taking into consideration existing and future (Sentinel) satellite missions, as well as the spectral, spatial and temporal resolutions of the satellite data.
\end{abstract}

Keywords: Satellite remote sensing, urban climate, urban parameters.

\section{INTRODUCTION}

Satellite remote sensing has been proven a valuable tool for monitoring, detecting and analyzing the physical and the artificial environment. At the same time, successful methods that are based on satellite data, have been developed and have a wide range of applications. Rosu et al. [1] studied horizontal ground displacements due to earthquake with the use of correlation techniques on satellite images, while Radhika et al. [2] detected cyclone damage on building structures from pre- and post- storm satellite images, highlighting the contribution of these methods to the impact reduction of natural disasters. Furthermore, satellite images have been used to study both the natural procedures, like evapotranspiration [3] and near-surface ocean currents [4], and the artificial environment, like the albedo and the emissivity of the city urban core [5]; critical parameters for the study of the urban climate.

Modifications in urban climate can affect considerably the energy consumption of buildings and subsequently influence energy fluxes within the urban environment [6]. Resilience and climate adaptability plans for the thermal environment at the urban scale are usually based on in situ measurements and urban modeling. In most cases the cascade modeling approach is followed: at first a mesoscale model at resolution ranging from $1 \mathrm{~km} \mathrm{x} 1 \mathrm{~km}$ to $500 \mathrm{~m} \times 500 \mathrm{~m}$ is used to define air and skin (land and buildings) temperatures and secondly and on the basis of the first stage results, areas of particular interest in terms of the thermal environment are selected and are further examined with the use of urban canopy layer models at improved spatial resolution (e.g. $30 \mathrm{~m} \times 30 \mathrm{~m}$ ).

*Address correspondence to this author at the Department of Environmental Physics, Panepistimiopolis, Build PHYS-V, Athens 157 84, Greece; E-mail: ckartali@phys.uoa.gr
In particular, the cascade modelling approach (extended to local scale) depends on the representation of urban areas by including a different number of physical processes, with the potential to affect the surface energy exchanges, within a) atmospheric numerical models of varying degree of complexity in terms of the physical processes [7] and b) microclimatic models [8]. In particular the following steps are considered necessary: a) energy and water fluxes are measured and/or modelled at local scale; b) fluxes of carbon and pollutants are also modelled and their spatio-temporal distributions are estimated; c) fluxes are dynamically simulated using numerical models. To this end, the application of the cascade modeling approach depends on the use of such urban parameters as: Land Surface Albedo (LSA), Land Surface Emissivity (LSE) and Land Surface Temperature (LST), [7]. It also depends on an adequate knowledge of land use/land cover (LULC), especially with respect to the vegetation cover of the area concerned.

The above parameters may be estimated through field campaigns; yet the spatial and temporal scales of such campaigns may be limited. Earth Observation (EO) may also provide the above parameters in a good mix of temporal and spatial resolutions, thus allowing a reliable application of the cascade modeling approach.

\section{ANALYSIS}

\subsection{Land Surface Emissivity}

Land Surface Emissivity is an important urban/climatic parameter as it reflects the capacity of the material to emit in the long wave part of the electromagnetic spectrum. In several climate adaptability plans, typical values for LSE are used, a fact which limits the accuracy of the estimation of the energy budget in the area concerned as well as the flows of 
energy between parts of the city. Furthermore the same LSE values are used for large parts of the urban area, despite the intense mix of materials in urban areas.

Satellite derived LSE products are used in meso-scale models simulations. Daily emissivity maps (MODIS Level 2 emissivity product) are available at $1 \mathrm{~km}$ spatial resolution. The classification-based emissivity method proposed as in [9], is used as developed with the use of linear Bidirectional Reflectance Distribution Function (BRDF) models. Such models utilize spectral coefficients derived from laboratory measurements of material samples. They also use structural parameters as derived from approximate descriptions of the cover type [10]. LSE can be also estimated with high resolution satellite data taking into account the 'mixed pixels' problem and the emissivity angular anisotropy [11].

LSE can be also derived at improved spatial resolutions. In the following example, three Landsat TM images at $30 \mathrm{~m}$ resolution, as acquired over metropolitan Athens during the warm season of the year (April to August 2005), are processed. For each of these images, the methodology applied is described in Sobrino et al. (2004) [12] and Stathopoulou et al. (2007) [13]. Following a composite LSE image was produced as a result of the overlay of LSE images and considering a mean LSE value for each pixel. In this way, a seasonal LSE image of Athens was produced (Fig. 1) showing lower LSE values in central and NW suburbs of Athens as compared to the $\mathrm{N}$ and $\mathrm{NE}$ ones, a fact which implies the presence of less vegetation and green open spaces in these areas. This information facilitated the detailed re-calculation of the outgoing long wave radiation as well as of the energy budget in the Athens area.

\subsection{Land Surface Albedo}

Satellite derived Land Surface Albedo products are used as inputs in meso-scale models simulations. LSA can be estimated from white-sky (completely diffuse) and black-sky (direct beam) albedo products as retrieved from satellite observations for each elementary (dependent on the spatial resolution of the sensors) surface. It should be mentioned that satellite observations do not directly measure LSA; to this end spectral albedo is derived by directional integration of land surface reflectance recorded at the sensor.

LSA may be defined at spatial resolutions ranging from 1 $\mathrm{km}$ (MODIS, NOAA/AVHRR) to $30 \mathrm{~m}$ (Landsat TM), or less. In the event of meso-scale modelling parameterization, $1 \mathrm{~km}$ derived LSA time series are used. In terms of microclimatic models, LSA can be derived from high spatial resolution satellite images. In Fig. (2), LSA is derived from a Landsat 5 satellite image, acquired over metropolitan Athens under cloud free atmospheric conditions on 8/4/2005. The methodology applied is described in Liang et al. (2001) [14].

\subsection{Land Use and Land Cover}

The definition of land use and land cover is considered important for a number of interlinked reasons. Depending on the use of land and the type of materials at the surface (land cover), significant changes may occur in the energy budget of the area concerned as a critical number of parameters such as albedo, thermal capacity, thermal conductivity and emissivity may differ from one part of the urban web to the other or may be modified even in short periods of time. In addition, changes in surface roughness may substantially influence atmospheric circulation patterns at the local scale. Existing satellite missions are capable of providing land use and land cover maps at spatial resolution as high as $1 \mathrm{~m}$. In most cases, an adequate spatial resolution is considered around 30-100 m, depending the size of the city or the size of the particular area of interest within a city (e.g. the historical centre). In terms of the temporal resolution, it depends on the selection of the spatial one as the higher the latter, the poorer the former. In any case and taken the slow changes in land use/land cover, temporal resolution of roughly 15-30 days is considered adequate.

Of particular concern in urban areas is the presence of vegetation cover, as urban green ameliorates the heat island observed in cities, decreases land surface temperature and air temperature and supports the circulation of air masses within the city, and especially along green belts which may exist in a city. The estimation of vegetation cover is given through the Normal Difference Vegetation Index (NDVI); the latter is calculated with the use of satellite measurements in channels in the visible and near infrared parts of the spectrum. Fig. (3) provides a snapshot of the vegetation cover for the greater urban agglomeration of Athens based on Landsat 5 satellite image, i.e. having the same spatial resolution as Figs. (1 and 2) above. Low scores (in brown) reflect built areas, whereas high scores (dark green) correspond to areas with high vegetation cover.

\subsection{Land Surface Temperature}

In urban climatology, LST is a key input parameter used in algorithms to estimate net radiation, sensible and latent heat flux, thermal inertia, surface urban heat island (SUHI) intensity, precipitable water, evapotranspiration, urbaninduced surface runoff and surface moisture [15-18].

Satellite observations of LST have also been used successfully for urban landscape management, urban environmental quality monitoring, urban risk analysis, surface urban heat island studies, energy parameters analysis, such as the cooling degree days, or bioclimatic parameters, such as the thermal discomfort index. A critical issue is the spatial and temporal resolution of satellite data used for the estimation of LST. As in the case of land use/land cover, the higher the spatial resolution, the lower the temporal one. LANDSAT and ASTER satellites provide the best spatial resolutions, from 60 to $90 \mathrm{~m}$ respectively, yet they have poor revisit times of the order of 16 days. Recent satellite missions (MODIS on board NASA Aqua and Terra satellites) enhance the range of available thermal data (as provided by NOAA/AVHRR) at a spatial resolution of $1 \mathrm{~km}$ and of temporal resolution which allows diurnal monitoring. METEOSAT also provides LST at 15 minutes interval, yet at a spatial resolution of $4 \mathrm{~km}$, a fact which leads to the need to apply 


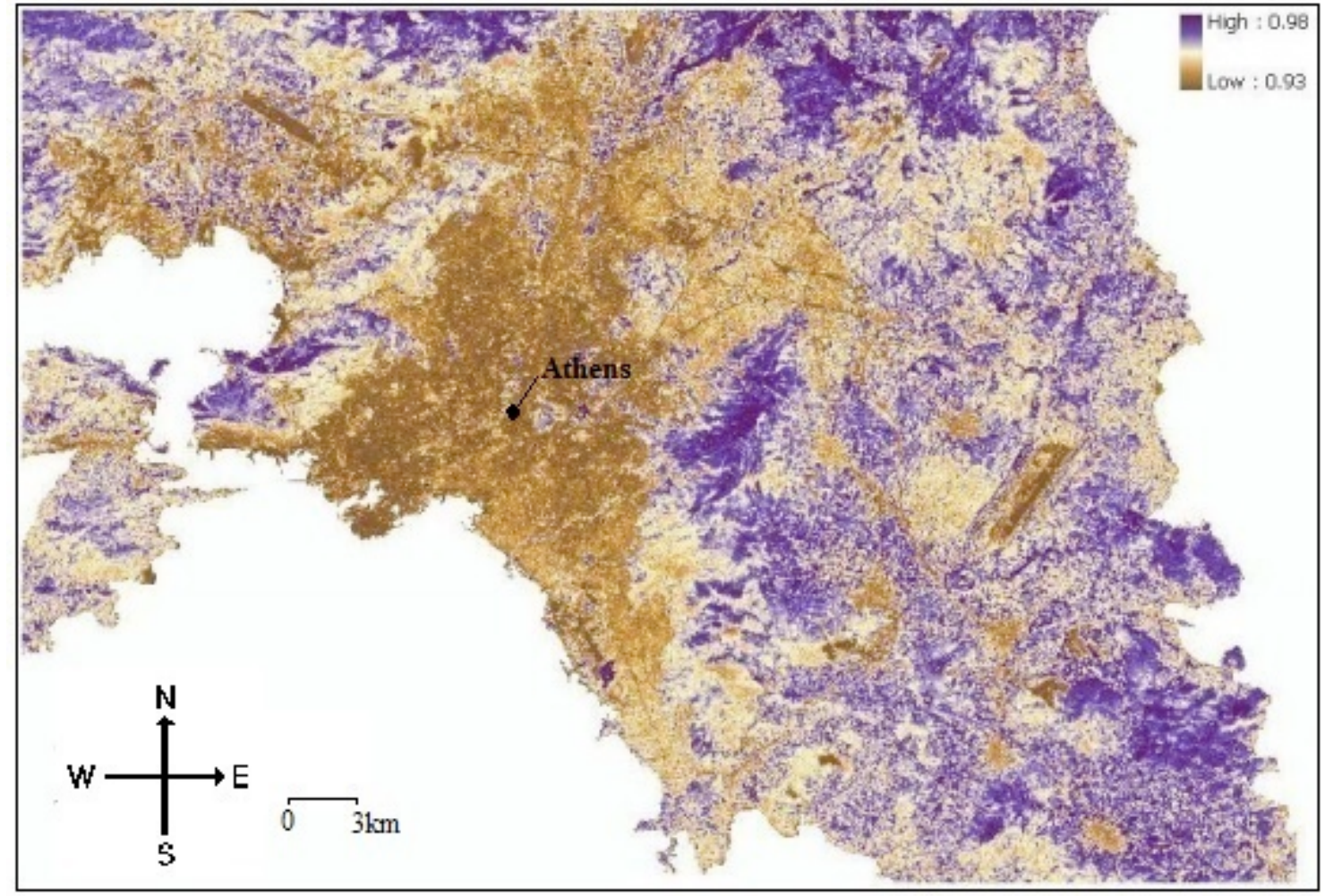

Fig. (1). Seasonal surface emissivity image of Athens (April - August 2005).

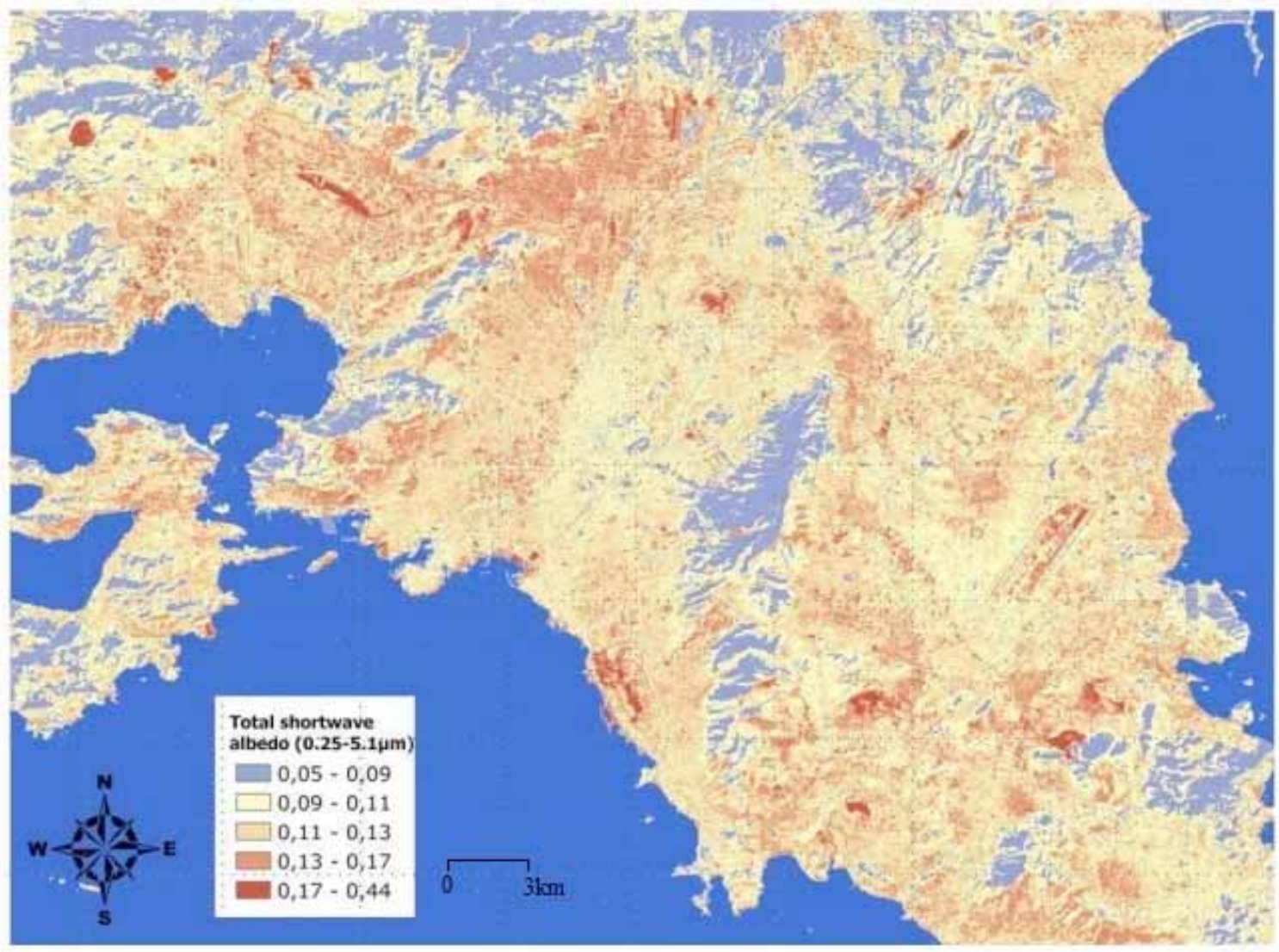

Fig. (2). Example image of total shortwave albedo for Athens on 8/4/2005. 




Fig. (3). Composite NDVI image of Athens for the warm season (April - August 2005).
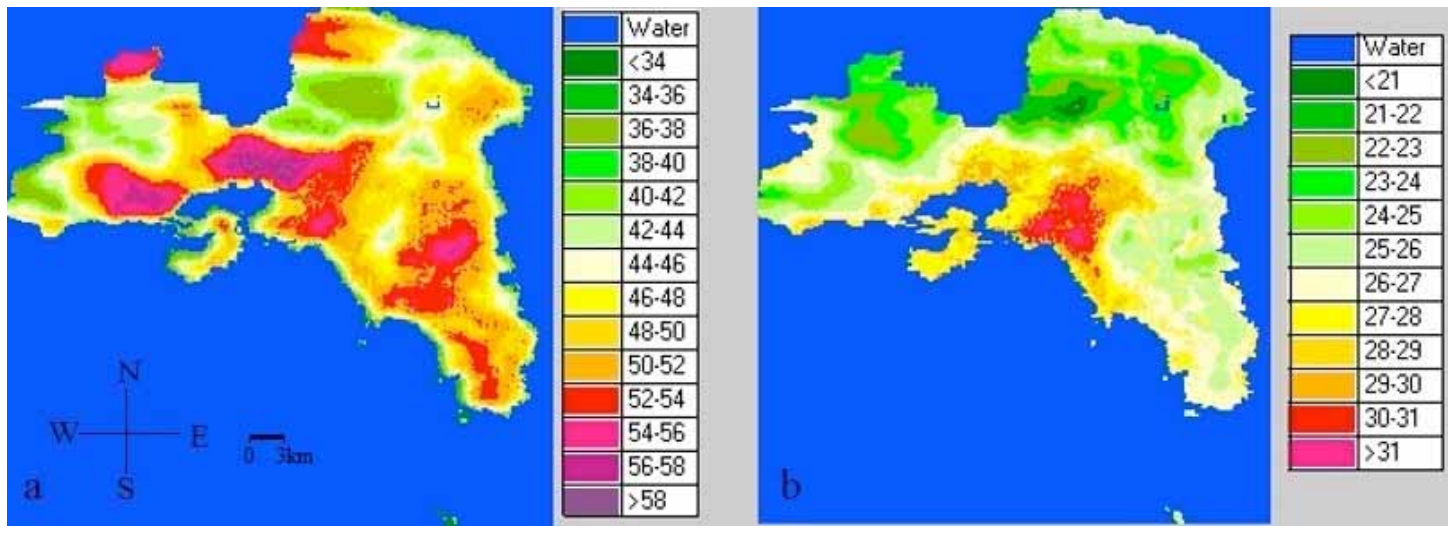

Fig. (4). Land Surface Temperature $\left({ }^{\circ} \mathrm{C}\right)$ at spatial resolution of $1 \mathrm{~km}$ for the Attica region at a) 11:00 UTC and b) 23:00 UTC.

Table 1. Potential of earth observation to support resilience and climate adaptibility plans.

\begin{tabular}{|c|l|}
\hline $\begin{array}{c}\text { Parameter needed for an Urban Resilience and Climate Adaptability } \\
\text { Plan }\end{array}$ & $\begin{array}{c}\text { Overall assessment of the potential of EO to support an Urban Resili- } \\
\text { ence and Climate Adaptability Plan }\end{array}$ \\
\hline \hline Land Surface Emissivity (LSE) & $\begin{array}{l}\text { Positive. } \\
\text { LSE is extracted at high spatial resolution, a fact which is highly beneficial } \\
\text { for the detailed estimation of the energy budget in the urban web, especially } \\
\text { in areas where increased temperatures are systematically observed. } \\
\text { Supportive for cascade modelling in the urban environment, i.e. subsequent } \\
\text { use of a mesoscale atmospheric model and an urban canopy layer model. }\end{array}$ \\
\hline
\end{tabular}


Table 1. contd...

\begin{tabular}{|c|c|}
\hline $\begin{array}{l}\text { Parameter needed for an Urban Resilience and Climate Adaptability } \\
\text { Plan }\end{array}$ & $\begin{array}{l}\text { Overall assessment of the potential of EO to support an Urban Resili- } \\
\text { ence and Climate Adaptability Plan }\end{array}$ \\
\hline Land Surface Albedo (LSA) & $\begin{array}{l}\text { Positive. } \\
\text { LSA is extracted at high spatial resolution, a fact which is highly beneficial } \\
\text { for the detailed estimation of the energy budget in the urban web, especially } \\
\text { in areas where land cover is modified due to anthropogenic activities. } \\
\text { Supportive for cascade modelling in the urban environment, i.e. subsequent } \\
\text { use of a mesoscale atmospheric model and an urban canopy layer model. }\end{array}$ \\
\hline Land use/Land cover (LULC) & $\begin{array}{l}\text { Positive. } \\
\text { Highly supportive for a) the recognition of changes in the urban web which } \\
\text { may be related to the increase/decrease of anthropogenic sources of heat b) } \\
\text { the application of mesoscale atmospheric models as well as urban canopy } \\
\text { ones. }\end{array}$ \\
\hline Land surface temperature (LST) & $\begin{array}{l}\text { In this case, resolutions counteract as high spatial resolution results in poor } \\
\text { temporal one and vice versa. In the event of mesoscale atmospheric models, } \\
\text { a spatial resolution of } 1 \mathrm{~km} \text { may be considered adequate at least in medium } \\
\text { and large urban centers. } \\
\text { Use of higher spatial resolution of the order of } 90 \text { to } 120 \text { meters is beneficial } \\
\text { for "hot spots" definition, i.e. urban areas which systematically present } \\
\text { higher LSTs as compared to the average one. It is also highly beneficial for } \\
\text { the extraction of the relationship between LST and air temperature. }\end{array}$ \\
\hline Surface Urban Heat Island (SUHI) & $\begin{array}{l}\text { Positive. } \\
\text { SUHI can be detected and adequately mapped, even at spatial resolution of } 1 \\
\mathrm{~km} \text {. Accordingly, the estimation of the intensity of SUHI is strongly sup- } \\
\text { ported. }\end{array}$ \\
\hline
\end{tabular}

downscale techniques so as to improve spatial resolution with potential reduction to accuracy, as some of the radiometric information may be lost.

Following, and for demonstration purposes, the split window algorithm developed by Coll et al. (1994) [19] is applied for NOAA/AVHRR, based on the aggregate spatial knowledge of LSE (see section 1) for the application area, as well as on the atmospheric water vapour content for the observation day. Results are presented in Fig. (4a, b).

The mid-morning summer LST spatial profile demonstrates the development of a negative SUHI, i.e. extended dry surfaces of bare soil or low vegetation in the surrounding rural areas presenting higher LST values than the urbanized surfaces of the Athens basin. The latter as characterized by lower sky view factor and higher thermal capacity, exhibit lower warming rate to incident solar radiation than the rural areas at the periphery of the city.

\section{CONCLUSION}

Finally, Table 1 summarizes the above analysis and provides a qualitative assessment of the potential of Earth
Observation to support the development of resilience and climate adaptability plans for the thermal environment at the urban scale.

It should be mentioned that spatial and temporal resolutions may vary considerably depending on the satellite mission. In addition, the choice of temporal/spatial resolution depends on the research application and in particular on the size of the urban area, the degree of inhomogeneity of land use/land cover, and the type of model applied (for instance mesoscale $v s$. urban canopy layer). To date, satellite data in a wide range of spectral, spatial and temporal resolutions are available, thus facilitating the estimation of land and air temperatures as well as the side and roof temperatures of city constructions. A potential limitation of Earth Observation is the presence of clouds which occlude the land surface from the satellite sensor.

\section{CONFLICT OF INTEREST}

The authors confirm that this article content has no conflicts of interest. 


\section{ACKNOWLEDGEMENTS}

This work is funded by ESA under the "Support for training of European young scientists within the framework of the DRAGON cooperation 2012-2016" program.

\section{REFERENCES}

[1] Rosu A, Pierrot-Deseilligny M, Delorme A, Binet R, Klinger, Y. Measurement of ground displacement from optical satellite image correlation using the free open-source software MicMac. ISPRS J Photogrametry Remote Sens 2015; 100: 48-59.

[2] Radhika S, Tamura Y, Matsui M. Cyclone damage detection on building structures from pre- and post-satellite images using wavelet based pattern recognition. J Wind Eng Ind Aerod 2015; 136: 2333.

[3] Rahimi S, Sefidkouhi MAG, Raeini-Sarjaz M, Valipour M. Estimation of actual evapotranspiration by using MODIS images (a case study: Tajan catchment). Arch Acker Pfl Boden 2015; 61: 695-709.

[4] Yang H, Arnone R, Jolliff J. Estimating advective near-surface currents from ocean color satellite images. Remote Sens Environ 2015; 158: 1-14

[5] Stathopoulou M, Synnefa A, Cartalis C, Santamouris M, Karlessi T, Akbari H. A surface heat island study of Athens using highresolution satellite imagery and measurements of the optical and thermal properties of commonly used building and paving materials. Int J Sustain Energ 2009; 28: 59-76.

[6] Santamouris M, Papanikolaou N, Livada I, et al. On the impact of urban climate on the energy consumption of buildings. Sol Energy 2001; 70: 201-16.

[7] Best J, Grimmond CSB. Analysis of the seasonal cyclewithin the first international urban land-surface model comparison. BoundLay Meteorol 2013; 146: 421-46.

[8] Cartalis C, Stathopoulou M, Mitraka Z, Chrysoulakis N. Use of earth observation to support urban modelling parameterization in bridge. In: Chrysoulakis N, Castro EA, Moors EJ, Eds. Understand- ing urban metabolism: A Tool for Urban Planning. London: Taylor \& Francis (Routledge) 2014; pp. 58-68.

[9] Snyder WC, Wan Z, Zhang Y, Feng Y-Z. Classification-based emissivity for land surface temperature measurement from space. Int J Remote Sens 1998; 19: 2753-74.

[10] Snyder WC, Wan Z. BRDF models to predict spectral reflectance and emissivity in the thermal infrared. Trans Geosci Remote Sens 1998; 36: 214-25.

[11] Mitraka Z, Chrysoulakis N, Kamarianakis Y, Partsinevelos P Tsouchlaraki A. Improving the estimation of urban surface emissivity based on sub-pixel classification of high resolution satellite imagery. Remote Sens Environ 2012; 117: 125-34.

[12] Sobrino JA, Jimenez-Munoz JC, Paolini L. Land surface temperature retrieval from LANDSAT TM 5. Remote Sens Environ 2004; 90: 434-40.

[13] Stathopoulou M, Cartalis C, Petrakis M. Integrating Corine Land Cover data and Landsat TM for surface emissivity definition: application to the urban area of Athens, Greece. Int J Remote Sens 2007; 28: 3291-304.

[14] Liang S. Narrowband to broadband conversion of land surface albedo i algorithms. Remote Sens Environ 2001; 76: 213-8.

[15] Voogt JA, Oke TR. Thermal remote sensing of urban areas. Remote Sens Environ 2003; 86: 370-84.

[16] Arnfield AJ. Two decades of urban climate research: A review of turbulence, exchanges of energy and water, and the urban heat island. Int J Climatol 2003; 23: 1-26.

[17] Gamba P, Dell'Aqua F, Dasarathy BV. Urban remote sensing using multiple data sets: Past, present and future. Inform Fusion 2005; 6 : 319-26.

[18] Stathopoulou M, Cartalis C. Use of satellite remote sensing in support of urban heat island studies. Adv Build Energy Res 2007; 1: 203-12.

[19] Coll C, Caselles V, Sobrino JA, Valor E. On the atmospheric dependence of the split window equation for land surface temperature. Int J Remote Sens 1994; 15: 105-22.

(C) Cartalis et al.; Licensee Bentham Open.

This is an open access article licensed under the terms of the Creative Commons Attribution Non-Commercial License (http://creativecommons.org/licenses/by-nc/3.0/) which permits unrestricted, non-commercial use, distribution and reproduction in any medium, provided the work is properly cited. 